\title{
Oxidative Stress in Non-alcoholic Fatty Liver Disease. An Updated Mini Review
}

\author{
Anna Pia Delli Bovi ${ }^{1+\neq}$, Francesca Marciano ${ }^{1,2+}$, Claudia Mandato ${ }^{3 *}$, Maria Anna Siano ${ }^{1}$, \\ Marcella Savoia ${ }^{2}$ and Pietro Vajro ${ }^{1}$ \\ 1 Pediatrics Section, Department of Medicine and Surgery, Scuola Medica Salernitana, University of Salerno, Baronissi, Italy, \\ ${ }^{2}$ Department of Molecular Medicine and Medical Biotechnologies, University of Naples Federico II, Naples, Italy, \\ ${ }^{3}$ Department of Pediatrics, Santobono-Pausilipon Children's Hospital, Naples, Italy
}

OPEN ACCESS

Edited by:

Daniel E. Francés, CONICET Instituto de Fisiología Experimental (IFISE), Argentina

Reviewed by:

Marcelo Roma

CONICET Instituto de Fisiología Experimental (IFISE), Argentina Ana J. Fernández-Alvarez, IIBBA-CONICET Leloir Institute

Foundation, Argentina

*Correspondence:

Claudia Mandato

cla.mandato@gmail.com

tThese authors have contributed equally to this work and share first authorship

¥Present address: Anna Pia Delli Bovi, Residency Program in Pediatrics,

University of Siena, Siena, Italy

Specialty section: This article was submitted to

Gastroenterology,

a section of the journal

Frontiers in Medicine

Received: 16 August 2020 Accepted: 01 February 2021 Published: 26 February 2021

Citation:

Delli Bovi AP, Marciano F, Mandato C, Siano MA, Savoia M and Vajro $P$

(2021) Oxidative Stress in

Non-alcoholic Fatty Liver Disease. An Updated Mini Review.

Front. Med. 8:595371.

doi: 10.3389/fmed.2021.595371
Non-alcoholic fatty liver disease (NAFLD) is a challenging disease caused by multiple factors, which may partly explain why it remains still orphan of an adequate therapeutic strategy. Herein we focus on the interplay between oxidative stress (OS) and the other causal pathogenetic factors. Different reactive oxygen species (ROS) generators contribute to NAFLD inflammatory and fibrotic progression, which is quite strictly linked to the lipotoxic liver injury from fatty acids and/or a wide variety of their biologically active metabolites in the context of either a two-hit or a (more recent) multiple parallel hits theory. An antioxidant defense system is usually able to protect hepatic cells from damaging effects caused by ROS, including those produced into the gastrointestinal tract, i.e., by-products generated by usual cellular metabolic processes, normal or dysbiotic microbiota, and/or diet through an enhanced gut-liver axis. Oxidative stress originating from the imbalance between ROS generation and antioxidant defenses is under the influence of individual genetic and epigenetic factors as well. Healthy diet and physical activity have been shown to be effective on NAFLD also with antioxidant mechanisms, but compliance to these lifestyles is very low. Among several considered antioxidants, vitamin E has been particularly studied; however, data are still contradictory. Some studies with natural polyphenols proposed for NAFLD prevention and treatment are encouraging. Probiotics, prebiotics, diet, or fecal microbiota transplantation represent new therapeutic approaches targeting the gut microbiota dysbiosis. In the near future, precision medicine taking into consideration genetic or environmental epigenetic risk factors will likely assist in further selecting the treatment that could work best for a specific patient.

Keywords: non-alcoholic fatty liver disease, oxidative stress, antioxidants, obstructive sleep apnea syndrome, gut microbiota, obesity, metabolic syndrome

\section{INTRODUCTION}

The term non-alcoholic fatty liver disease (NAFLD) was originally coined by Ludwig et al. (1). It indicated a hepatopathy similar to that of alcohol abuse without alcohol consumption history, and it is now reputed as the hepatic component of metabolic syndrome $(2,3)$. It affects approximately a quarter of the population, mostly obese, and has no approved drug therapy. Although NAFLD 
is generally benign, $\sim 20-30 \%$ of patients develop liver inflammation, fibrosis/cirrhosis (non-alcoholic steatohepatitis, NASH), and, in some cases, hepatocellular carcinoma $(4,5)$. Moreover, patients with NAFLD are at higher risk of cardiovascular diseases. Because of the lack of valid therapies and of the obesity pandemic, NAFLD is one of rapidly growing indications for liver transplantation (6).

Most NAFLD patients are obese and present a mild systemic inflammation, which hampers insulin signaling [insulin resistance (IR)], playing a relevant role in the pathomechanism of liver damage $(7,8)$. Recently, in consideration of this association, an international group of experts highlighted the poor coherence of the term non-alcoholic fatty liver disease and proposed that of metabolic (dysfunction)-associated fatty liver disease (9). The reason why some patients with simple steatosis show a progression to more severe hepatic injury, whereas others do not, was in part simplified by the so-called "two-hit" model, founded on IR, and the deposits of relatively inert triglycerides (TGs) within the liver as initial damage. This first event was thought to be due to a "second hit" generated by oxidative stress (OS) or depletion of ATP (10) with the activation of an inflammatory cytokine cascade contributing to the development of NASH necroinflammation and fibrosis (10-12).

However, it has been found that hepatic lipid accumulation in NAFLD occurs mostly as relatively inert TGs droplets, and this is nowadays regarded as a protective rather than a deleterious mechanism, by impeding the storage of free fatty acids (FFAs), which are the actual harmful agents in this hepatopathy. Most recent evidences underline that inflammation may even precede fat accumulation, which would become only a response (12, 13). As schematically shown in Figure 1, hepatic FFAs originate from lipolysis in adipose tissue and dietary lipids. Moreover, particularly in conditions of IR, they may also be synthesized de novo (so-called de novo lipogenesis) from carbohydrates in the liver and be deposited as TG droplets (hepatic steatosis), or exported contributing to the very low-density lipoprotein pool (14).

The previous "two-hit theory" has therefore led the way to the "multiple parallel hits theory" (12), with the contribution of a number of "multiple parallel (and not sequential)" offenders acting with different combinations, at times synergistically, to generate NAFLD. These offenders include, in addition to IR (3) and OS, hormones secreted from the adipose tissue, intestinal dysbiosis, increased intestinal permeability, and also exposure to environmental agents such as endocrine disruptors (15) and particulate matter $(\mathrm{PM})(16,17)$ interacting among themselves in individuals predisposed by genetic and epigenetic factors.

Genes that modulate hepatic fat accumulation and retinol metabolism [i.e., transmembrane 6 superfamily member 2 (TM6SF2), variants of patatin-like phospholipase domain which contain protein 3 (PNPLA3), membrane-bound Oacyltransferase domain containing 7 (MBOAT7), hydroxysteroid $17 \beta$-dehydrogenase (HSD17B13), and glucokinase regulator (GCKR)] (9) and the deregulation of microRNAs are known to influence NAFLD development and progression (18).

In addition, also genetic variants involved in OS regulation play an important role in NAFLD pathogenesis. These genes include SOD2 gene, coding for the manganese-dependent superoxide dismutase (MnSOD); UCP3, coding for the uncoupling protein 3 , a mitochondrial transporter that enhances the proton leak of mitochondrial inner membrane and unhooks the oxidative phosphorylation; uncoupling protein 2 (UCP2), regulating oxidative metabolism and mitochondrial lipid efflux; and MARC1 (A165T), which codes for the mitochondrial amidoxime reducing component 1 , a protein involved in the neutralization of reactive oxygen species (ROS) $(19,20)$.

The NAFLD story is even more complex than this, as it may start even before conception and pregnancy. Epigenetic changes, comprising microRNA features, may cause fetal reprogramming during the pregnancy of an obese mother and transgenerational transmission of the susceptibility to NAFLD in childhood and progression to NASH across the lifetime. Moreover, improving obese mothers' diet reduces fetal hypoxemia and counteracts metabolic pathways able to generate OS, liver injury precursors, and lipotoxicity in non-human primates (21-23).

On the basis of the most recent literature, herein we will focus especially on OS because the understanding of a main role for OS in NAFLD development and progression can have important preventive and therapeutic implications for possible novel treatments.

\section{OXIDATIVE STRESS AND ITS ROLE IN NAFLD PATHOLOGY}

OS is caused by a discrepancy between ROS generation and antioxidant defenses, which lead to DNA and tissue damage $(24,25)$. It may occur both for the increasing production of prooxidant products and the dysfunction of the antioxidant system.

Although it is essential to tissue repair, it may conceal also negative features implying the development and/or exacerbation of several systemic diseases and conditions [e.g., mental/neurological diseases $(26,27)$, inflammatory bowel diseases (28), cardiovascular disease (29), and cancer (30)]. Starting from these premises, one can therefore easily predict that OS represents an important mediator triggering low-grade inflammation also in metabolic syndrome and in the progression of NAFLD into NASH (31-35).

ROS, in fact, appear tightly involved in those processes that lead to hepatic fibrosis (36). Multiple interlaced pro-oxidative triggers operate together with the mitochondrial dysfunction as a likely common denominator of OS (37). In NASH, there are more evidences of mitochondrial DNA and protein abnormalities being responsible for the increase of OS $(38,39)$. A decreased oxidative capacity of the electron transport chain (ETC) and mutations in complex II could also lead to a condition of "electron leakage" (40), meaning that the electron normal flow could be interrupted, binding with oxygen to produce superoxide or hydrogen peroxide. Moreover, the levels of glutathione (GSH) peroxidase, MnSOD, and catalase seem to be low in NASH, so that the capability of the mitochondria to reduce ROS levels is reduced. In NASH patients, an increased activity of CYP2E1 (41) has been also observed, an important microsomal source 
ENVIRONMENT

High Fat/Caloric Diet, Fructose,Sedentary life; EDCs/BPA; particulate matter; drugs

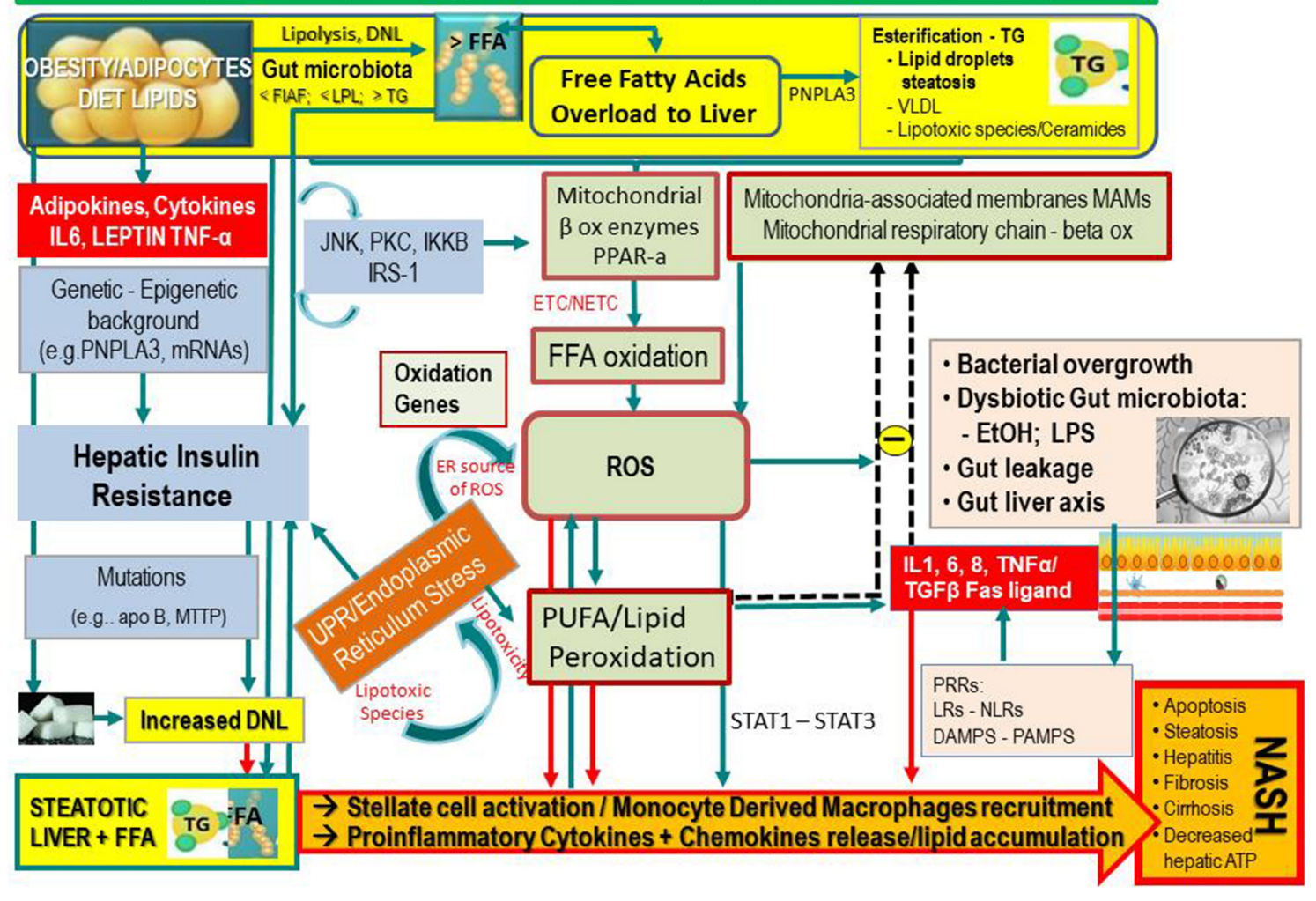

FIGURE 1 | Simplified flow of pathogenetic events in non-alcoholic fatty liver disease. The figure shows the crosstalk between systems and metabolisms in the pathogenetic events leading to fatty liver and its progression to NASH. In the upper part (yellow lane), one can note that hepatic FFAs derive from lipolysis in adipose tissue, dietary lipids, and DNL from COH in the liver. These FFAs may either be stored in the liver as TG droplets (hepatic steatosis) or be exported as VLDL to adipose tissue. FFA overload may concur in the hepatic IR (vertical light azur lane), which interplays with the JNK, PKC system where the activation of JNK1 may impair insulin signaling via serine phosphorylation of IRS1. The UPR/ER stress is a source of ROS and of lipotoxic species and plays a link between the OX stress and IR. Upon disruption of mitochondria-associated membranes (MAM) integrity, miscommunication directly or indirectly disrupts Ca ${ }^{2+}$ homeostasis and increases ERS (brown box) and OS, leading to defective insulin secretion and accelerated lipid droplet formation in hepatocytes. Inflammatory mediators (adipokines, cytokines) in large part arrange the progression from NAFLD to NASH (red boxes) in case of shortage of endogenous antioxidant molecules. These mediators are variously triggered by oxidative hepatic environment [ROS, lipid peroxidation] and bacterial overgrowth (pink boxes) after the infraction of the gut barrier (gut leakage) by bacterial Eth and enhanced intestinal permeability, which allows lipopolysaccharides (a) to activate PRR-LRs - NLRs-DAMPS - PAMPS and (b) to concur with ROS/PUFA in the inhibition of the mitochondrial respiratory chain. Lipotoxic lipid species lead to hepatic stress and subsequent release of extracellular vesicles, cytokines, chemokines, and DAMPs from hepatocytes. This results in enrolment of bone marrow immune cells. As shown in the lower part of the figure, liver-resident stellate/KCs are activated by several triggers (mainly ROS, gut microbiota), resulting in the release of chemokine (C-C motif) ligand 2 (CCL2) and other proinflammatory cytokines (i.e., TNF- $\alpha, I L-1$, and IL-6). The oxidative hepatic environment also stimulates transcription programs (STAT-1 and STAT-3) promoting T-cell recruitment and hepatic disease progression. Overall, the scenario ultimately leads to the recruitment of bone marrow-derived monocytes and neutrophils that further contribute to the inflammatory response and a rebound ROS production. A number of genetic variants are implicated in NAFLD development, and progression is shown. BPA, bisphenol A; CYP, cytochrome; $\mathrm{COH}$, carbohydrates; DAMPS, damage-associated molecular patterns; DNL, de novo lipogenesis; EDC, endocrine-disrupting chemicals; ETC, electron transport chain; Eth, ethanol; FFA, free fatty acids; FIAF, fasting-induced adipose factor; HNE, hydroxynonenal; IKKB, inhibitor of nuclear factor $\kappa B$ kinase subunit $\beta$; IL, interleukin; IRS, insulin receptor substrate; JNK, c-Jun N-terminal kinase; LPL, lipoprotein lipase; LPS, lipopolysaccharide; LRs, lectin receptors; MAM, mitochondria-associated membrane; MDA, malondialdehyde; mRNA, microRNA; MTTP, microsomal triglyceride transfer protein; NAFLD, non-alcoholic fatty liver disease; NASH, non-alcoholic steatohepatitis; NLRs, NOD-like receptors; NF-кB, nuclear factor $\kappa$-light-chain enhancer of activated B cells; NTC non-electron transport chain; PAMPs, pathogen-associated molecular patterns; PKC, protein kinase; PNPLA3, patatin-like phospholipase domain-containing protein 3; PRR, pattern recognition receptor; PPAR, peroxisome proliferator-activated receptor; PUFA, polyunsaturated fatty acids; ROS, reactive oxygen species; TG, triglyceride; TNF, tumor necrosis factor; UPR, unfolded protein response; VLDL, very low-density lipoprotein; <, decrease; >, increase.

of OS, especially together with C47T polymorphisms of SOD2 (encoding MnSOD) (41-45).

In the development of NASH, OS probably occurs not only due to the saturation of the antioxidant machinery secondary to the increased pro-oxidant species production and its direct insult. In the liver, actually, these conditions trigger lipid peroxidation by specific polyunsaturated fatty acids (PUFAs), along with the formation of highly reactive aldehyde products [e.g., malondialdehyde (MDA) and 4-hydroxy-2-non-enal (4$\mathrm{HNE}$ )]. Overall, these events appear involved in the diffusion of 
ROS and reactive nitrogen species (RNS) into the extracellular space, perpetuating intracellular and tissue damage. Moreover, hepatic OS may result from gut microbiota (GM)-related inflammation and the disturbance in the normal functions of endoplasmic reticulum [so-called ER stress (ERS)] (see below) [(37, 46); Figure 1].

\section{IMPLICATION OF THE OXIDATIVE STRESS IN HEPATIC INJURY}

ROS/RNS (i.e., hydrogen peroxide, superoxide anion radical, peroxynitrite, and hydroxyl radical), and not lipid peroxidation byproducts, are the responsible for cytokine elevations (47) such as tumor necrosis factor $\alpha$ (TNF- $\alpha)$, transforming growth factor $\beta$, interleukin 8 (IL-8), and Fas ligand. The sum of these events results in NAFLD development (25). The oxidative hepatic environment in obesity furthermore promotes the signal transduction and activation of transcription programs (STAT-1 and STAT-3) that promote T-cell recruitment and liver damage with disease progression up to its malignant transformation [(48); Figure 1].

\section{OS and Hepatic Injury: Possible Implications in NAFLD Progression}

Hepatocyte damage involves a cascade of events leading to NAFLD progression into NASH and cirrhosis: damageassociated molecular patterns, discharged from damaged hepatocytes, lead to the release of chemokines and cytokines from Kupffer cells (KCs) and the recruitment of monocytederived macrophages. ROS directly and indirectly contribute to stellate cell activation and to chronic inflammatory response with up-regulation of proinflammatory cytokines (TNF- $\alpha$, IL-6, and IL-1), apoptosis, and development of hepatic fibrosis [(49-51); Figure 1].

In conditions of progressive NAFLD, OS can also result from increased ROS generation due to impairment of mitochondria caused by an overload of FFAs and an increase of their metabolism, lipotoxicity, and hypoxia, as well as ROS production through NADPH-oxidase isoforms associated to ligand-receptor link or by activated inflammatory cells (49).

Evidences suggest that lipotoxicity mediated by FFAs (52) may induce disruption of ER homeostasis, known as "unfolded protein response," an intracellular signaling activated by the accumulation of unfolded/misfolded proteins. Thanks to it, ER can communicate the folding status of its proteins to the rest of the cell, particularly to the nucleus, and so activate genes transcription. As a result, the ERS, a term that includes also several other mechanisms conducing to ROS generation, occurs (37), and this leads to

- increased endoplasmic reticulum oxidoreduction-1 (ERO-1) activity, the enzyme that catalyzes disulfide bond formation (53) with $\mathrm{H}_{2} \mathrm{O}_{2}$ production;

- upregulation of CCAAT/enhancer-binding protein homologous protein (Chop), a proapoptotic mechanism (54);
- calcium leakage from ER, which increases its flow through mitochondrial membranes leading to proapoptotic mitochondrial membrane permeabilization (55);

- GSH depletion (56), altering GSH-oxidized glutathione balance, which is essential to redox homeostasis; and

- inhibition of nuclear factor, erythroid 2-related factor 2, a factor encoding for antioxidant proteins (57).

The cross talk between ERS and ROS (Figure 1) appears relevant in the pathogenesis of NAFLD (58). Mitochondria-associated membranes (MAMs) represent a physical junction between ER and mitochondria, allowing $\mathrm{Ca}^{2+}$, lipids, and ROS exchange. Because normal communication between mitochondria and ER depends on MAM structural and functional integrity, lack of calcium homeostasis may lead to ERS and OS increase, defective insulin secretion, and accelerated lipid droplet formation in hepatocytes. The steps involve apoB misfolding, impaired lipoprotein secretion, and lipogenesis stimulation. On these bases, protecting the ER via the administration of antioxidants or activation of peroxisome proliferator-activated receptor (PPAR) has been suggested as promising avenues against hepatic steatosis $(59,60)$.

Studies in rodents show the existence of a link between ERS and regulation of hepatic iron metabolism both in ASH and NASH models mainly due to the capacity of ferrous iron to catalyze the production of hydroxyl radical $\left(\mathrm{OH}^{-}\right)$ from $\mathrm{H}_{2} \mathrm{O}_{2}$, deriving by peroxisomal $\beta$-oxidation $(52,61,62)$. Interestingly, iron deficiency too may reduce the cell antioxidant capability by inhibiting heme oxygenase-1 by Bach1 (63). Beyond doubt, it is not always simple to study the progression of a disease, especially in humans in vivo, and establish if a certain factor is exactly the cause or the effect of NASH. Moreover, a disagreement often happens between animal models and clinical studies due to several factors such as gut microflora differences and patient inclusion criteria/ethnicity-related predisposition, respectively (37).

In order to assess the redox state in NAFLD/NASH, some markers of OS and antioxidants have been studied in NAFLD and NASH models, both clinical and experimental. OS biomarkers include nitric oxide, lipid damage products (lipid peroxides, thiobarbituric acid reactive substances/MDA), hydroperoxides, 8 -isoprostane, 4-HNE, DNA oxidation product [CYP2E1 and 8-hydroxydeoxyguanosine $(8-\mathrm{OH}-\mathrm{dG})]$, and protein oxidation products (nitrotyrosine, protein carbonyl). All these had increased activities in most NAFLD/NASH clinical models evaluated. On the contrary, antioxidant markers (superoxide dismutase, catalase, glutathione peroxidase, reduced glutathione) measured in rodent models showed decreased activities mainly in NASH (64).

\section{GUT MICROBIOTA AND INTESTINE PERMEABILITY AS A CAUSE OF OXIDATIVE STRESS}

\section{Gut Microbiota as a Source of ROS}

Human commensal microbiota (Figure 1) generates physiological ROS levels in intestinal human epithelial 
cells. Basically, aerobic cell systems are exposed to oxygen free radicals $(65,66)$, and their damaging role relies on their concentrations. When the levels of ROS exceed antioxidant defenses, harmful effects on cells may occur, conducing to uncontrolled proliferation, inflammation, and/or apoptosis $(67,68)$. This is what happens also in obesity and its related hepatometabolic comorbidities, including NAFLD progression to NASH (see below). ROS can also operate as second messengers in intracellular signaling stimulated by proinflammatory cytokines and growth factors and by the quick and reversible oxidative inactivation of proteins having thiol groups sensitive to oxidants (69). In inflammation and obesity, ROS generation is probably strictly related with activation of nuclear factor $\kappa$-light-chain enhancer of activated B cells (NF- $\kappa B$ ) and degradation of NF- $\kappa B$ inhibitor (I $\mathrm{KB}$ ), making NF- $\mathrm{KB}$ more transcriptionally active (70-72). As shown in Figure 1, a quantitative or qualitative (in term of dysbiosis) bacterial alteration (small intestine bacterial overgrowth) is also concatenated with OS through the inhibition of mitochondrial respiratory chain.

\section{Interaction Between Gut Microbiota, OS, and Intestinal Permeability in NAFLD}

Gut mucosal barrier separates, functionally and physically, the luminal content from the underlying compartment that, in addition to gut epithelia, includes immune, vascular, and structural elements in the lamina propria. The intestinal mucosa is constantly exposed to oxidants and carcinogens taken in from diet and/or bacteria, whose chronic exposure may cause production of free radicals leading to redox imbalance and subsequent DNA damage, disturbing the intestinal metabolic equilibrium (73).

GM plays an important role in different processes (metabolic, nutritional, physiological, and immunological) involved in maintaining a healthy status $(69,74)$. Its qualitative and quantitative composition differs in the distinct parts of gastrointestinal (GI) tract because of the influences by different conditions [e.g., age, dietary habits, ethnicity, delivery mode, exposure to therapies, pathogens, and contact with several environmental stimuli (75-78)]. Perturbation of GM composition, called "dysbiosis," has been recognized in diseases associated not only with the GI tract [e.g., inflammatory bowel disease (79)] but also with systemic conditions such as obesity, diabetes mellitus, autism, depression, and NAFLD (80). While a quite clear causal role of a specific GM has been demonstrated in murine models of NAFLD (e.g., unhealthy diet dependent shift from Bacteroidetes to Firmicutes), recognition of a corresponding human microbiome signature is more difficult. In fact, it may be hindered by the components of associated metabolic syndrome and several other confounding factors. Anyway, Gram-negative harmful bacteria release lipopolysaccharide (LPS), lipoteichoic acid, flagellin, lipoprotein, or other toxins recognized by the pattern recognition receptors (PRRs) expressed on the surface of innate immune system cells. Similarly, structurally conserved motifs present on the surface of different types of pathogens (pathogen-associated molecular patterns) are recognized and bound by PRRs, inducing mitochondrial ROS production and nuclear gene expression.

PRR classes sensitive to the microbiota's factors are Toll-like receptor (TLR), Rig-1-like receptor, Nod-like receptor, and Ctype lectin receptor. They induce the NF- $\mathrm{KB}$ pathway activation and enhance the inflammatory response when proinflammatory cytokines and antibacterial factors are released $(81,82)$. Differently, small formylated peptides produced and released by commensal bacteria are recognized by another kind of receptor, known as formylated peptide receptors. These are G-proteins linked to surface receptors of neutrophils and macrophages, stimulating ROS synthesis in phagocytes and epithelial cells (83). In particular, their activation stimulates superoxide anion production by NADPH oxidase 1, increasing ROS levels in cell cytoplasm that lead to an inflammatory response and increase of cell OS (84). As a consequence of cell stress, mitochondrial and bacterial DNA may be integrated in the nuclear genome causing the alteration of cellular gene expression.

Intestinal mucosa permeability has an important role in modulating how GM can influence also other parts of the body. An alteration of its barrier function consents to the GM and its endotoxins to cross the intestinal epithelium and the endothelial barrier (85) traveling into systemic circulation and reaching different target organs $(75,86)$.

There are many evidences according to which gut bacteria are involved in the pathogenesis of liver injury induced by alcohol, and gut leakiness promotes proinflammatory bacterial products reaching the liver, thus initiating the proinflammatory cascade that causes alcoholic steatohepatitis (ASH). Alcohol impairs intestinal epithelial cell permeability in vitro through a mechanism mediated by OS (87), supporting therefore the idea that OS may be the main cause of alcohol-induced intestinal leakage $(88,89)$.

In NAFLD, with a quite similar mechanism, endogenous ethanol produced by some microbial species [e.g., Escherichia genus members of the Proteobacteria phylum induced by highfat diet; (90)] is able to induce the formation of ROS by HSC cells and impair intestinal integrity. The latter allows LPS to reach hepatic TLRs activating and further enhancing oxidative, inflammatory, and fibrogenetic mechanisms (75, 90, 91, 91-94).

GM seems to mediate the progression from simple steatosis to NASH. In particular, increased Gram-negative bacteria expose KCs to an elevated amount of LPS and upregulation of PRRs (37). It has been hypothesized that the endocytosis of LPS by KC could induce upregulation of cytokine receptors, especially the TNF- $\alpha$ receptor, which seems to be also involved in the increased ROS production (95). Activated KCs have a role in IR, fibrosis development, and inflammation amplification.

Also, the association between obstructive sleep apnea syndrome (OSAS) and NASH severity seems to correlate with endotoxemia increase and gut barrier function alteration, conducing to increased hepatic susceptibility to endotoxemia mediated by TLR-4 (96). An alarming 60\% OSAS incidence has been reported in pediatric NAFLD $(97,98)$. This disorder of breathing during sleep has been associated with fatty acid accumulation in the liver and inflammation caused by frequent nocturnal hypoxia (NH), IR, OS, and adipokine dysregulation 
(99). Growing experimental evidences link the alternation of $\mathrm{NH}$ with normoxia (so-called chronic intermittent hypoxia) caused by OSAS to NAFLD development and progression $(49,100)$. A study that compared healthy controls and NAFLD patients (some of which with OSA/NH), identified $\mathrm{NH}$ as a possible source of OS in NAFLD. OSA/NH is common in pediatric patients with liver biopsy-proven NAFLD and is associated with more advanced liver injury and histological disease $(97,98)$. Intermittent hypoxia conduces to tissue hypoxia and can lead to OS, mitochondrial malfunction, inflammation, and sympathetic nervous system hyperactivation. As a consequence, intermittent hypoxia causes IR, impairment of hepatic lipid metabolism pathways (84), and hepatic steatosis and fibrosis, each of which is involved into NAFLD development and/or progression [(101); Figure 2].

\section{THERAPEUTIC STRATEGIES}

\section{Non-enzymatic Anti-oxidants Defenses}

Antioxidants are substances that inhibit the oxidation of any biomolecule (102), neutralizing the harmful effects of oxidation caused by free radicals, maintaining therefore the redox homeostasis. Antioxidants are either synthesized endogenously (e.g., GSH, superoxide dismutase) or taken from the diet. Anthocyanins, lycopene, coenzyme Q10, flavonoids, $\beta$-carotene, lipoic acid, selenium, lutein, catechins, and vitamins A, C, and $\mathrm{E}$ are among the many substances normally present in foods that possess a high antioxidant activity. As reported in the table, they can be also classified in two large groups on the basis of the presence/absence of their enzymatic action [(103114); Table 1].

Despite the above premises, antioxidants as potential pharmacological agents have hitherto not appeared extremely effective in vivo as either a preventive or therapeutic tool in NAFLD (31, 117-122). Studies that have investigated the role of vitamin $\mathrm{E}$ as a treatment of NASH confirm that it acts against pathogenic mechanisms conducting to liver damage and $\mathrm{NASH}$, thanks to its antioxidant and anti-inflammatory activity (123-126). The antioxidant power of vitamin $\mathrm{E}$ is due to the hydroxyl group in the tocochromanol ring, which neutralizes free radicals and ROS by donating hydrogen. The major forms of tocopherol and tocotrienol are $\alpha, \beta-, \gamma-$, and $\delta$-, with the antioxidant activity of the $\delta$-isoform being weaker than the others, the vitamin $\mathrm{E}$ isoforms are also involved in many other activities (Table 2). Among the vitamin E isoforms, the $\alpha$ tocopherol, has other different properties independently from its antioxidant ability: it can inhibit the activity of protein kinase $\mathrm{C}$, reducing the proliferation of different cell types (vascular smooth muscle cells, mesangial cells, neutrophils, monocytes/macrophages, fibroblast, and various cancer cell lines) and the 5-lipoxygenase pathway, inhibiting the release of proinflammatory cytokine IL-1 $\beta$.

\section{Clinical Trials of Vitamin E for NAFLD: Vitamin E in the Clinics}

Available data are still conflicting. The largest trials with vitamin E in NAFLD are the PIVENS (Pioglitazone vs. Vitamin E vs. Placebo for the Treatment of Non-diabetic Patients with Non-alcoholic Steatohepatitis) (127) and the TONIC (Treatment of Non-alcoholic Fatty Liver Disease in Children) (121) trials. The first showed that both drugs tested in adults ameliorated steatosis, lobular inflammation, and hepatocellular ballooning, but did not ameliorate fibrosis. Vitamin E but not pioglitazone induced a clinical improvement in NASH. The TONIC trial, which evaluated therapeutic intervention with vitamin $\mathrm{E}$ vs. metformin in children with NAFLD, showed that both improved hepatocellular ballooning and the NAFLD activity score (NAS), but neither vitamin E nor metformin decreased alanine aminotransferase (ALT) values or hepatic steatosis, inflammation, or fibrosis in NASH. The reasons of these disappointing results depend on the need of better patient selection and protocols. Interestingly, a most recent systematic review and meta-analysis (1,317 patients from 15 randomized controlled trials) concluded that vitamin E improves biochemical and histological outcomes in adults and pediatric patients, with a significant negative association between transaminases levels and vitamin E dosage-more satisfactorily ranging between 400 and $800 \mathrm{IU}$. However, while adults receiving vitamin $\mathrm{E}$ improved significantly transaminases, fibrosis, and NAS both at early and late follow-up, children showed more significant changes at longterm follow-up, which could partly explain the negative results obtained by certain short-term studies (128). Some still unsolved safety concerns should be considered as well. Vitamin E, in fact, has been suspected to have a dichotomous suppressive and promoting activity with respect to tumorigenesis [e.g., cocancerogenic in prostate cancer; $(25,129)]$ possibly explainable by still poorly studied host gene-supplement interactions (130). In our opinion, further carefully designed studies are still necessary for substantiating this view and supporting optimum procedures in terms of both efficacy and safety profiles.

Results from multiple regression models showed a significant negative association between ALT, AST levels, and vitamin E dosage-more favorably between 400 and 800 IU.

A quite large number of other nutraceutical antioxidants that seem to improve NASH through more than one pathway (Table 2 and Figure 3) include but are not limited to the following:

- Curcumin $(37,103)$, with effects on different amino acids, bile acids, tricarboxylic acid cycle, and GM (131, 132), although only few human clinical trials are available (132-134).

- PUFAs of omega-3 series (PUFA omega-3), which may act as an antioxidant, have a role in modulating OS improving the defense capacity against an increased oxidative burden (135, 136).

Thanks to them, the cellular metabolism switch from lipogenesis and triacylglycerol accumulation to fatty acid oxidation thus plays a role in decreasing fatty liver. Furthermore, they have anti-inflammatory activity and enhance insulin sensitivity (103). Clinical trials evaluating the efficacy of n-3 PUFA (including docosahexaenoic acid and eicosapentaenoic acid) on systemic OS in NAFLD and NASH have shown controversial results. While n-3 PUFA supplementation appears useful in NAFLD early stages (137), unfortunately, total (enzymatic and nonenzymatic) antioxidant capacity is not enough to attenuate the hepatic damage (35). Interestingly, dietary antioxidant 


\section{OBSTRUCTIVE SLEEP APNEA}

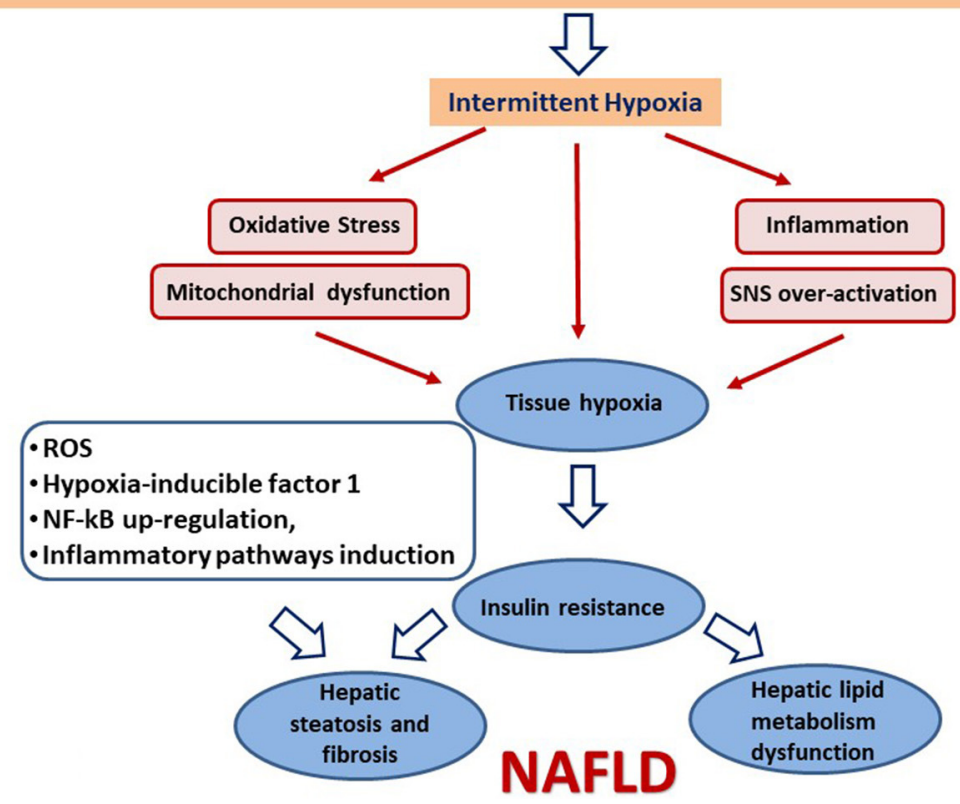

FIGURE 2 | Association between obstructive sleep apnea and the development and evolution of non-alcoholic fatty liver disease. Intermittent hypoxia leads to tissue hypoxia, OS, mitochondrial dysfunction, inflammation, and overactivation of the sympathetic nervous system (SNS). Generated reactive $\mathrm{O}_{2}$ species (ROS) may amplify liver injury by activating hypoxia-inducible factor 1, a transcriptional activator and master regulator of $\mathrm{O}_{2}$ homeostasis during hypoxia, and by up-regulating nuclear factor $\kappa$-light-chain enhancer of activated B cells (NF-кB), with subsequent downstream induction of inflammatory pathways. As a consequence, this involves insulin resistance, dysfunction of key steps in hepatic lipid metabolism, atherosclerosis, and hepatic steatosis and fibrosis, each of which is pertinent to the development and/or progression of non-alcoholic fatty liver disease (NAFLD) (98-101).

intake is significantly lesser in NASH patients than in healthy controls (138).

- Among polyphenols, blueberry leaf polyphenols appear to have a positive effect on hepatic mitochondrial dysfunction and redox homeostasis, whereas bergamot polyphenolic formulation seems to improve IR, hepatocellular ballooning, inflammation, and fibrosis $(115,116)$.

\section{Probiotics and Prebiotics: Other Tools Improving Defenses Against OS}

Improving defenses against OS through modulation of the GM composition and functionality offers a promising means of managing or treating metabolic disorders (74).

Probiotics are living microorganisms with beneficial health activity on the host. For example, they are able to improve GM composition and reduce LPS serum amount and liver TLR4, delaying liver disease progression $(81,98,99)$. Lactobacilli and bifidobacteria are the most commonly used, usually present in dietary supplements or fermented foods such as yogurt and cultured milk (100). Changing the resident GM composition and the gut lumen, they create an anti-inflammatory environment, obtaining decreased proinflammatory bacterial products and gut barrier integrity improvement. Lactobacillus rhamnosus GG (LGG) is the subject of numerous studies (139-144); it has different beneficial effects on the intestinal function through dysbiotic microbiota normalization $(100,144,145)$ and reducing intestinal OS (146). A recent meta-analysis found a beneficial effect of probiotics also on hepatic antioxidative capacity as mirrored by the increase of SOD and GSH-PX activities and decrease of MDA content (147). A daily LGG treatment in alcohol-fed rats significantly improves severity of ASH and gut leakiness induced by alcohol, decreases intestinal and liver OS markers and inflammation, and normalizes the gut barrier task, avoiding to trigger liver disease (148). GM regulates also the powerful antioxidant glutathione and amino acid metabolism (144). It is not surprising therefore that fecal microbiota transplantation (FMT) from control donors in steatotic rats has been found to have beneficial effects in terms of decrease of portal hypertension through insulin sensitivity improvement mediated by the endothelial nitric oxide synthase signaling pathway, a pathway clearly involved in the antioxidant mechanisms (149). A pilot study of FMT in NASH is currently undergoing to evaluate whether restoration of healthful GM through FMT from lean donors (FMT-L) ameliorates NASH (150).

Similarly, "prebiotics" are fermentable carbohydrates that selectively modulate microbiota composition and/or activity, resulting in a beneficial effect for the host (146). Finally, also synbiotics (i.e., a combination of prebiotics and probiotics) have shown a positive effect on GM and have been proposed as a support for the treatment of NAFLD (151). 
Summing up, the modulation of quality and diversity of every single human microbiota appears therefore an appealing tool in the management of intestinal ROS, OS, inflammation, and

TABLE 1 | Antioxidants with and without enzymatic action

\begin{tabular}{|c|c|}
\hline $\begin{array}{l}\text { Enzymatic } \\
\text { antioxidants }\end{array}$ & Non-enzymatic antioxidants \\
\hline \multirow[t]{2}{*}{$\begin{array}{l}\text { Superoxide dismutase } \\
\text { (SOD) }\end{array}$} & $\begin{array}{l}\text { Low-molecular-weight compounds } \\
\text { Glutathione, thioredoxin, lactoferrin }\end{array}$ \\
\hline & $\begin{array}{l}\text { Endogenous substances } \\
\text { Lipoic acid, melatonin, albumin, bilirubin, uric acid, } \\
\text { polyunsaturated fatty acids omega } 3\end{array}$ \\
\hline \multirow[t]{2}{*}{ Catalase (CAT) } & $\begin{array}{l}\text { Flavonoid polyphenols } \\
\text { Silymarin }(104,105) \\
\text { Blueberry leaf, bergamot polyphenols }(115,116)\end{array}$ \\
\hline & $\begin{array}{l}\text { Stilbenes } \\
\text { Resveratrol }(106,107)\end{array}$ \\
\hline \multirow[t]{2}{*}{ Glutathione peroxidase } & $\begin{array}{l}\text { Herbs } \\
\text { Erchen decoction, danshen, berberine (108) }\end{array}$ \\
\hline & $\begin{array}{l}\text { Carotenoids } \\
\beta \text {-Carotene, astaxanthin, lycopene, } \beta \text { - } \\
\text { cryptoxanthin, lutein, fucoxanthin, crocetin } \\
(109,110)\end{array}$ \\
\hline \multirow[t]{2}{*}{ Paraoxonase 1 (PON 1) } & $\begin{array}{l}\text { Phenolic compounds } \\
\text { Açai (111) }\end{array}$ \\
\hline & $\begin{array}{l}\text { Vitamins } \\
\text { Ascorbic acid (vitamin } C), \alpha \text {-tocopherol [vitamin E, } \\
\text { vitamin } A \text {, vitamin } D(112-114)]\end{array}$ \\
\hline
\end{tabular}

some metabolic anomalies caused by dysbiosis (152). Moreover, it is suggested that changes in GM occurring upon prebiotic consumption may be due to gut bacterial functions improvement. In other words, products generated by Lactobacillus and metabolites derived by microbiota, such as antioxidants and fatty acids, could be employed for target medicine in the management of liver disease including NAFLD (146).

\section{OTHER THERAPEUTIC STRATEGIES}

\section{Drugs}

Ursodeoxycholic acid (UDCA) remains one of the most studied drugs: in addition to exerting a possible therapeutic effect on NAFLD by modulating autophagy and apoptosis dysregulation, UDCA appears to have also antioxidant properties (153).

TABLE 2 | Activities influenced by vitamin E isoforms.

\footnotetext{
I. Regulation of the inflammatory response

II. Gene expression

III. Membrane-bound enzymes

IV. Cellular signaling

V. Cell proliferation
}

VI. Regulation of several enzymes involved in signal transduction: Protein kinase C (PKC), protein phosphate 2A (PP2A), 5-lipoxygenase, cyclooxygenase 2 (COX-2), and monocyte chemoattractant protein 1 (MCP-1) VII. Regulation of several factors in the mitogen-activated protein kinase (MAPK) signal transduction pathway

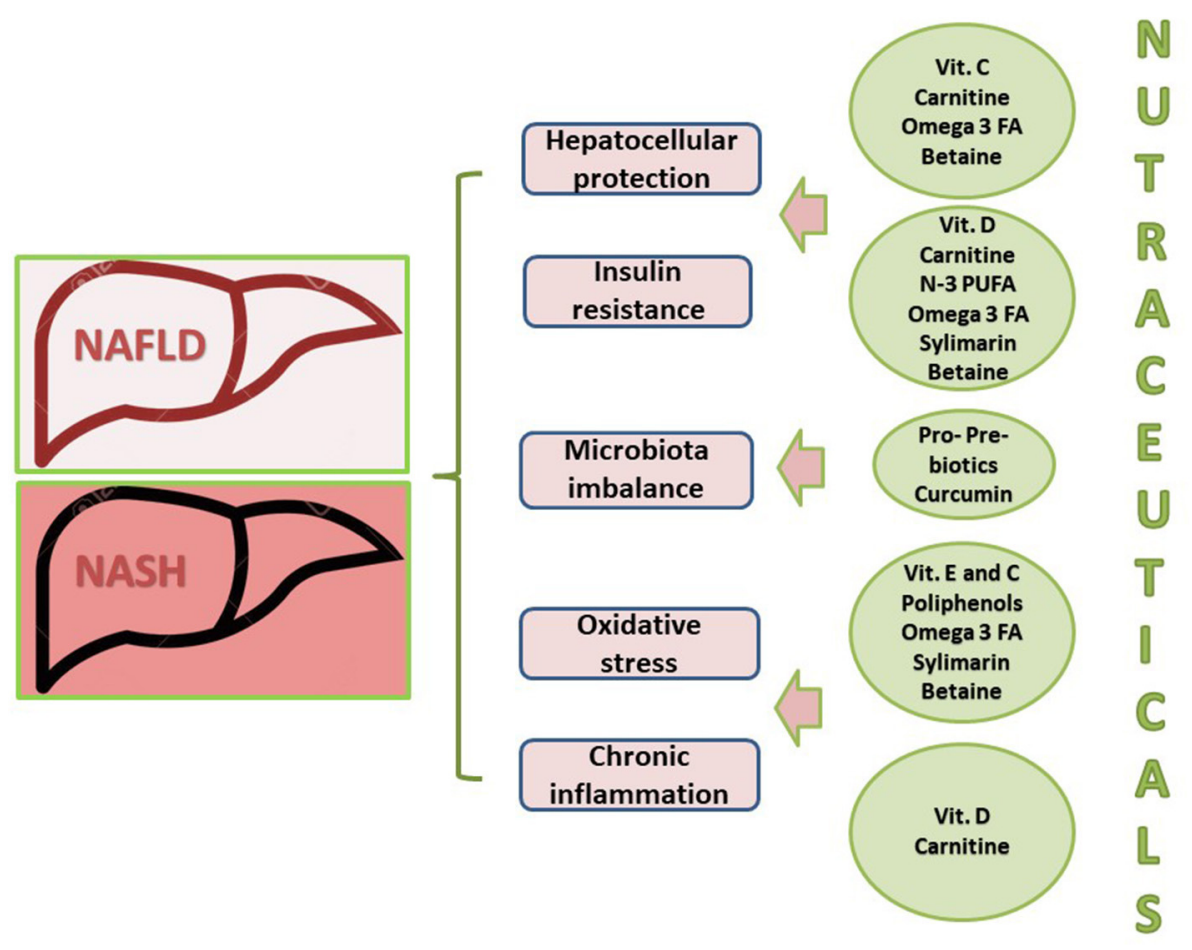

FIGURE 3 | Multiple targets of nutraceuticals for the treatment of non-alcoholic fatty liver disease. FA, fatty acids; NAFLD, non-alcoholic fatty liver disease; NASH, non-alcoholic steatohepatitis. Adapted and modified by Del Ben et al. (103). 
A number of other drugs that have been tested for their influence on hepatic steatosis have still uncertain/elusive molecular mechanisms. There are several innovative agents currently undergoing phases II and III clinical trials with different targets (154).

Obeticholic acid, a semisynthetic bile acid analog, is an agonist of the farnesoid $\mathrm{X}$ receptor, which has anti-inflammatory and antioxidant activities (155).

Silymarin, a botanical product extracted from milk thistle, because of its antioxidant properties appears to improve NAFLD hypertransaminasemia and reduce liver disease progression in NASH, but at present, available results are inconclusive (156).

Cannabidiol, a chemical without psychotropic effects, has antioxidant and anti-inflammatory properties by acting on the endocannabinoid system. After stimulation of the G-proteincoupled receptors and their endogenous lipid ligands, it interferes with progression toward NASH $(26,157)$.

\section{Physical Activity}

Physical activity (PA) acts favorably in NAFLD primarily by reducing intrahepatic fat content with $\beta$-oxidation of fatty acids and lipogenesis regulation, enhancing the expression and activity of PPAR- $\gamma$, insulin sensitivity, and hepatoprotective autophagy, reducing hepatocyte apoptosis, and inflammation of the liver by decreasing the proinflammatory mediators. PA, moreover, has several beneficial effects on NAFLD also with the improvement of several antioxidants activity [e.g., catalase, SOD, glutathione peroxidase and reductase, glutathione-S-transferase, thioredoxin reductases, $\mathrm{NADH}$ cytochrome $\mathrm{B} 5$ reductase, and $\mathrm{NAD}(\mathrm{P}) \mathrm{H}$ quinone acceptor oxidoreductase], leading to decreased ROS production and proinflammatory cytokines (158).

\section{CONCLUDING REMARKS}

Our review exhibits that OS not counteracted by intact antioxidant defense system plays an important role in NAFLD/NASH with a number of other casual factors. Excessive FFA $\beta$-oxidation due to increased FFA fueling leads to excessive ROS formation, which, in turn, downregulates ETC, and nonETC systems, affect insulin sensitivity, hepatic lipid metabolism, and inflammatory responses by interacting with innate immune signaling (159).

Gut dysbiosis may induce further signaling processes, which engage the epithelium and immune/inflammatory cells. In these

\section{REFERENCES}

1. Ludwig J, Viggiano TR, McGill DB, Oh BJ. Nonalcoholic steatohepatitis: Mayo Clinic experiences with a hitherto unnamed disease. Mayo Clin Proc. (1980) 55:434-8.

2. Abenavoli L, Greco M, Milic N, Accattato F, Foti D, Gulletta E et al. Effect of Mediterranean diet and antioxidant formulation in nonalcoholic fatty liver disease: a randomized study. Nutrients. (2017) 9:870. doi: 10.3390/nu9080870

3. Buzzati E, Pinzani M, Tsochatzis EA. The multiple hit-pathogenesis of non-alcoholic fatty liver disease (NAFLD). Metabolism. (2016) 65:1038-48. doi: 10.1016/j.metabol.2015.12.012 conditions, GM may take advantage of the increased intestinal permeability and/or impairment of epithelial tight junctions. This results in an enhancement of the gut-liver axis with bacteria and endotoxin transit through the intestinal and endothelial vascular wall, ending up into hepatic and other systemic diseases as well.

The above scenario would suggest a therapeutic role of antioxidants in patients with fatty liver disease, but this approach has not been entirely translated yet in human (160), as most studies still derive from murine models with substantial differences in genetic background and in the digestive system; the need to perform more human studies appear evident (161).

Vitamin E has shown promising data but without significant benefit in fibrosis improvement (162). Several natural polyphenols and n-3 PUFA supplementation provided with a number of antioxidant, antiobesity, and anti-inflammatory effects could have potential in NAFLD prevention and treatment by acting on its multifactorial pathogenetic components, but also here data either to support or refuse their use are insufficient $(115,116)$.

In addition to healthy diet (e.g., a Mediterranean diet seems to reduce OS), probiotics, prebiotics, and fecal transplantation appear to be emerging strategies to modulate microbiota quality and diversity, in order to prevent and/or avoid gut damage. Avoidance of exposure to endocrine disruptors (15) and to ambient PM $(16,17)$ also appears strategic to add benefices to NAFLD.

Last but not least, the accurate assessment of NAFLDassociated genetic/epigenetic risk factors of diseases and likelihood of disease progression is going to aid to target individualized appropriate treatments (163).

\section{AUTHOR CONTRIBUTIONS}

FM and APDB collected literature and prepared the first draft of the manuscript. MS and MAS collected literature on specific areas and gave critical suggestions. PV gave critical suggestions, made substantial intellectual contributions to the study design, and manuscript preparation. CM provided a major intellectual input, verified/contributed to data analysis, and took over writing of the manuscript as and when required. All authors gave substantial contributions to the work and revised critically and approved the final manuscript.
4. Tiniakos DG, Vos MB, Brunt EM. Nonalcoholic fatty liver disease: pathology and pathogenesis. Annu Rev Pathol. (2010) 5:145-71. doi: 10.1146/annurev-pathol-121808-102132

5. Baffy G, Brunt EM, Caldwell SH. Hepatocellular carcinoma in non-alcoholic fatty liver disease: an emerging menace. J Hepatol. (2012) 56:1384-91. doi: 10.1016/j.jhep.2011.10.027

6. Mikolasevic I, Filipec-Kanizaj T, Mijic M, Jakopcic I, Milic S, Hrstic I, et al. Nonalcoholic fatty liver disease and liver transplantation - where do we stand? World J Gastroenterol. (2018) 24:1491-506. doi: 10.3748/wjg.v24.i14.1491

7. Sanyal AJ, Campbell-Sargent C, Mirshahi F, Rizzo WB, Contos MJ, Sterling RK, et al. Nonalcoholic steatohepatitis: association of insulin resistance 
and mitochondrial abnormalities. Gastroenterology. (2001) 120:1183-92. doi: 10.1053/gast.2001.23256

8. Fabbrini E, Sullivan S, Klein S. Obesity and nonalcoholic fatty liver disease: biochemical, metabolic, and clinical implications. Hepatology. (2010) 51:679-89. doi: 10.1002/hep.23280

9. Eslam M, Sanyal AJ, George J, International Consensus Panel. MAFLD: a consensus-driven proposed nomenclature for metabolic associated fatty liver disease. Gastroenterology. (2020) 158:1999-2014. doi: 10.1053/j.gastro.2019.11.312

10. Day CP, James OF. Steatohepatitis: a tale of two "hits"? Gastroenterology. (1998) 114:842-5. doi: 10.1016/s0016-5085(98)70599-2

11. Peverill W, Powell LW, Skoien R. Evolving concepts in the pathogenesis of NASH: beyond steatosis and inflammation. Int J Mol Sci. (2014) 15:8591638. doi: 10.3390/ijms15058591

12. Tilg $\mathrm{H}$, Moschen AR. Evolution of inflammation in nonalcoholic fatty liver disease: the multiple parallel hits hypothesis. Hepatology. (2010) 52:1836-46. doi: 10.1002/hep.24001

13. Yamaguchi K, Yang L, McCall S, Huang J, Yu XX, Pandey SK, et al. Inhibiting triglyceride synthesis improves hepatic steatosis but exacerbates liver damage and fibrosis in obese mice with nonalcoholic steatohepatitis. Hepatology. (2007) 45:1366-74. doi: 10.1002/hep.21655

14. Saponaro C, Gaggini M, Carli F, Gastaldelli A. The subtle balance between lipolysis and lipogenesis: a critical point in metabolic homeostasis. Nutrients. (2015) 7:9453-74. doi: 10.3390/nu7115475

15. Foulds CE, Treviño LS, York B, Walker CL. Endocrine-disrupting chemicals and fatty liver disease. Nat Rev Endocrinol. (2017) 13:445-57. doi: $10.1038 /$ nrendo.2017.42

16. Xu MX, Ge CX, Qin YT, Gu TT, Lou DS, Li Q, et al. Prolonged PM2.5 exposure elevates risk of oxidative stress-driven nonalcoholic fatty liver disease by triggering increase of dyslipidemia. Free Radic Biol Med. (2019) 130:542-56. doi: 10.1016/j.freeradbiomed.2018.11.016

17. Ding S, Yuan C, Si B, Wang M, Da S, Bai L, et al. Combined effects of ambient particulate matter exposure and a high-fat diet on oxidative stress and steatohepatitis in mice. PLoS ONE. (2019) 14:e0214680. doi: 10.1371/journal.pone.0214680

18. Gjorgjieva M, Sobolewski C, Dolicka D, Correia de Sousa M, Foti M. miRNAs and NAFLD: from pathophysiology to therapy. Gut. (2019) 68:2065-2079. doi: 10.1136/gutjnl-2018-318146

19. Taliento AE, Dallio M, Federico A, Prati D, Valenti L. Novel insights into the genetic landscape of nonalcoholic fatty liver disease. Int J Environ Res Public Health. (2019) 16:2755. doi: 10.3390/ijerph16152755

20. Al-Serri A, Anstee QM, Valenti L, Nobili V, Leathart JB, Dongiovanni P, et al. The SOD2 C47T polymorphism influences NAFLD fibrosis severity: evidence from case-control and intra-familial allele association studies. $J$ Hepatol. (2012) 56:448-54. doi: 10.1016/j.jhep.2011.05.029

21. Wesolowski SR, Mulligan CM, Janssen RC, Baker PR II, Bergman BC, D'Alessandro A, et al. Switching obese mothers to a healthy diet improves fetal hypoxemia, hepatic metabolites, and lipotoxicity in non-human primates. Mol Metab. (2018) 18:25-41. doi: 10.1016/j.molmet.2018.09.008

22. Baker PR 2nd, Friedman JE. Mitochondrial role in the neonatal predisposition to developing nonalcoholic fatty liver disease. J Clin Invest. (2018) 128:3692-703. doi: 10.1172/JCI120846

23. Bertrando S, Vajro P. NAFLD at the interface of the mother-infant dyad. Curr Pharm Des. (2020) 26:1119-25. doi: 10.2174/1381612826666200122153055

24. Sies H. Oxidative stress: a concept in redox biology and medicine. Redox Biol. (2015) 4:180-3. doi: 10.1016/j.redox.2015.01.002

25. Nagashimada M Ota T. Role of vitamin $\mathrm{E}$ in nonalcoholic fatty liver disease. IUBMB Life. (2019) 71:516-22. doi: 10.1002/iub.1991

26. Atalay S, Jarocka-Karpowicz I, Skrzydlewska E. Antioxidative and anti-inflammatory properties of cannabidiol. Antioxidants. (2019) 9:2. doi: 10.3390/antiox9010021

27. Yusuf M, Khan M, Robaian MA, Khan RA. Biomechanistic insights into the roles of oxidative stress in generating complex neurological disorders. Biol Chem. (2018) 399:305-19. doi: 10.1515/hsz-2017-0250

28. Kruidenier L, Verspaget HW. Oxidative stress as a pathogenic factor in inflammatory bowel disease-radicals or ridiculous? Aliment Pharmacol Ther. (2002) 16:1997-2015. doi: 10.1046/j.1365-2036.2002.01378.x
29. Sinha N, Dabla PK. Oxidative stress and antioxidants in hypertension-a current review. Curr Hypertens Rev. (2015) 11:132-42. doi: 10.2174/1573402111666150529130922

30. Bellot GL, Liu D, Pervaiz S. ROS, autophagy, mitochondria and cancer: Ras, the hidden master? Mitochondrion. (2013) 13:155-62. doi: 10.1016/j.mito.2012.06.007

31. Mandato C, Lucariello S Franzese A, Licenziati MR, Franzese A, Spagnuolo MI, Ficarella R, et al. Metabolic, hormonal, oxidative, and inflammatory factors in pediatric obesity-related liver disease. J Pediatr. (2005) 147:62-6. doi: 10.1016/j.jpeds.2005.02.028

32. Paravicini TM, Touyz RM. Redox signaling in hypertension. Cardiovasc Res. (2006) 71:247-58. doi: 10.1016/j.cardiores.2006.05.001

33. Trachootham D, Alexandre J, Huang P. Targeting cancer cells by ROSmediated mechanisms: a radical therapeutic approach? Nat Rev Drug Discov. (2009) 8:579-91. doi: 10.1038/nrd2803

34. Hardwick RN, Fisher CD, Canet MJ, Lake AD, Cherrington NJ. Diversity in antioxidant response enzymes in progressive stages of human nonalcoholic fatty liver disease. Drug Metab Dispos. (2010) 38:2293-301. doi: 10.1124/dmd.110.035006

35. Koek GH, Liedorp PR, Bast A. The role of oxidative stress in non-alcoholic steatohepatitis. Clin Chim Acta. (2011) 412:1297-305. doi: 10.1016/j.cca.2011.04.013

36. Rector RS, Thyfault JP, Uptergrove GM, Morris EM, Naples SP, Borengasser SJ, et al. Mitochondrial dysfunction precedes insulin resistance and hepatic steatosis and contributes to the natural history of non-alcoholic fatty liver disease in an obese rodent model. J Hepatol. (2010) 52:727-36. doi: 10.1016/j.jhep.2009.11.030333333

37. Tariq Z, Green JC, Hodson L. Are oxidative stress mechanisms the common denominator in the progression from hepatic steatosis towards nonalcoholic steatohepatitis (NASH). Liver International. (2014) 34:e180-90. doi: $10.1111 /$ liv. 12523

38. Pérez-Carreras M, Del Hoyo P, Martín MA, Rubio JC, Martín A, Castellano G, et al. Defective hepatic mitochondrial respiratory chain in patients with nonalcoholic steatohepatitis. Hepatology. (2003) 38:999-1007. doi: $10.1053 /$ jhep. 2003.50398

39. Berson A, De Beco V, Lettéron P, Robin MA, Moreau C, El Kahwaji J, et al. Steatohepatitis-inducing drugs cause mitochondrial dysfunction and lipid peroxidation in rat hepatocytes. Gastroenterology. (1998) 114:764-74. doi: 10.1016/s0016-5085(98)70590-6

40. Kawahara H, Fukura M, Tsuchishima M, Takase S. Mutation of mitochondrial DNA in livers from patients with alcoholic hepatitis and nonalcoholic steatohepatitis. Alcohol Clin Exp Res. (2007) 31:S54-60. doi: 10.1111/j.1530-0277.2006.00287.x

41. Chalasani N, Gorski JC, Asghar MS, Asghar A, Foresman B, Hall SD, et al. Hepatic cytochrome P450 2E1 activity in nondiabetic patients with nonalcoholic steatohepatitis. Hepatology. (2003) 37:544-50. doi: 10.1053/jhep.2003.50095

42. Varela NM, Quiñones LA, Orellana M, Poniachik J, Csendes A, Smok G, et al. Study of cytochrome P450 2E1 and its allele variants in liver injury of nondiabetic, nonalcoholic steatohepatitis obese women. Biol Res. (2008) 41:81-92.

43. El-Koofy NM, El-Karaksy HM, Mandour IM, Anwar GM, El-Raziky MS, El-Hennawy AM. Genetic polymorphisms in non-alcoholic fatty liver disease in obese Egyptian children. Saudi J Gastroenterol. (2011) 17:265-70. doi: 10.4103/1319-3767.82582

44. Namikawa C, Shu-Ping Z, Vyselaar JR, Nozaki Y, Nemoto Y, Ono $\mathrm{M}$, et al. Polymorphisms of microsomal triglyceride transfer protein gene and manganese superoxide dismutase gene in non-alcoholic steatohepatitis. J Hepatol. (2004) 40:781-6. doi: 10.1016/j.jhep.2004. 01.028

45. Nobili V, Donati B, Panera N, Vongsakulyanon A, Alisi A, Dallapiccola $\mathrm{B}$, et al. A 4-polymorphism risk score predicts steatohepatitis in children with nonalcoholic fatty liver disease. J Pediatr Gastroenterol Nutr. (2014) 58:632-6. doi: 10.1097/MPG.0000000000000279

46. Rolo AP, Teodoro JS, Palmeira CM. Role of oxidative stress in the pathogenesis of nonalcoholic steatohepatitis. Free Radic Biol Med. (2012) 52:59-69. doi: 10.1016/j.freeradbiomed.2011.10.003 
47. Pessayre D. Role of mitochondria in non-alcoholic fatty liver disease. J Gastroenterol Hepatol. (2007) 1:S20-7. doi: 10.1111/j.1440-1746.2006.04640.x

48. Grohmann M, Wiede F, Dodd GT, Gurzov EN, Ooi GJ, Butt T, et al. Obesity drives STAT-1-dependent NASH and STAT-3-dependent HCC. Cell. (2018) 175:1289-306. doi: 10.1016/j.cell.2018.09.053

49. Mann JP, Raponi M, Nobili V. Clinical implications of understanding the association between oxidative stress and pediatric NAFLD. Expert Rev Gastroenterol Hepatol. (2017) 11:371-82. doi: 10.1080/17474124.2017.1291340

50. Day CP. Pathogenesis of steatohepatitis. Best Pract Res Clin Gastroenterol. (2002) 16:663-78. doi: 10.1053/bega.2002.0333

51. De Knegt RJ. Non-alcoholic steatohepatitis: clinical significance and pathogenesis. Scand J Gastroenterol Suppl. (2001) (234):88-92. doi: 10.1080/003655201753265505

52. Gentile CL, Pagliassotti MJ. The endoplasmic reticulum as a potential therapeutic target in nonalcoholic fatty liver disease. Curr Opin Investig Drugs. (2008) 9:1084-8.

53. Gross E, Kastner DB, Kaiser CA, Fass D. Structure of Erolp, source of disulfide bonds for oxidative protein folding in the cell. Cell. (2004) 117:60110. doi: 10.1016/s0092-8674(04)00418-0

54. Song B, Scheuner D, Ron D, Pennathur S, Kaufman RJ. Chop deletion reduces oxidative stress, improves beta cell function, and promotes cell survival in multiple mouse models of diabetes. JClin Invest. (2008) 118:337889. doi: $10.1172 /$ JCI 34587

55. Deniaud A, Sharaf el dein O, Maillier E, Poncet D, Kroemer G, Lemaire C, et al. Endoplasmic reticulum stress induces calcium-dependent permeability transition, mitochondrial outer membrane permeabilization and apoptosis. Oncogene. (2008) 27:285-99. doi: 10.1038/sj.onc.1210638

56. Haynes CM, Titus EA, Cooper AA. Degradation of misfolded proteins prevents ER-derived oxidative stress and cell death. Mol Cell. (2004) 15:76776. doi: 10.1016/j.molcel.2004.08.025

57. Sugimoto H, Okada K, Shoda J, Warabi E, Ishige K, Ueda T, et al. Deletion of nuclear factor-E2-related factor-2 leads to rapid onset and progression of nutritional steatohepatitis in mice. Am J Physiol Gastrointest Liver Physiol. (2010) 298:G283-94. doi: 10.1152/ajpgi.00296.2009

58. Ashraf NU, Sheikh TA. Endoplasmic reticulum stress and Oxidative stress in the pathogenesis of Non-alcoholic fatty liver disease. Free Radic Res. (2015) 49:1405-18. doi: 10.3109/10715762.2015.1078461

59. Fujii J, Homma T, Kobayashi S, Seo HG. Mutual interaction between oxidative stress and endoplasmic reticulum stress in the pathogenesis of diseases specifically focusing on non-alcoholic fatty liver disease. World J Biol Chem. (2018) 9:1-15. doi: 10.4331/wjbc.v9.i1.1

60. Wang J, He W, Tsai PJ, Chen PH, Ye M, Guo J, et al. Mutual interaction between endoplasmic reticulum and mitochondria in nonalcoholic fatty liver disease. Lipids Health Dis. (2020) 19:72. doi: 10.1186/s12944-020-01210-0

61. Tan TC, Crawford DH, Jaskowski LA, Subramaniam VN, Clouston AD, Crane DI, et al. Excess iron modulates endoplasmic reticulum stressassociated pathways in a mouse model of alcohol and high-fat diet-induced liver injury. Lab Invest. (2013) 93:1295-312. doi: 10.1038/labinvest.2013.121

62. Masarone M, Rosato V, Dallio M, Gravina AG, Aglitti A, Loguercio C, et al. Role of oxidative stress in pathophysiology of nonalcoholic fatty liver disease. Oxid Med Cell Longev. (2018) 2018:9547613. doi: 10.1155/2018/9547613

63. Evstatiev R, Gasche C. Iron sensing and signalling. Gut. (2012) 61:933-52. doi: 10.1136/gut.2010.214312

64. Ore A, Akinloye OA. Oxidative stress and antioxidant biomarkers in clinical and experimental models of non-alcoholic fatty liver disease. Medicina. (2019) 55:26. doi: 10.3390/medicina55020026

65. Hensley K, Robinson KA, Gabbita SP, Salsman S, Floyd RA. Reactive oxygen species, cell signalling and cell injury. Free Radic Biol Med. (2000) 28:145662. doi: 10.1016/s0891-5849(00)00252-5

66. Valko M, Leibfritz D, Moncol J, Cronin MT, Mazur M, Telser J. Free radicals and antioxidants in normal physiological functions and human disease. Int $J$ Biochem Cell Biol. (2007) 39:44-84. doi: 10.1016/j.biocel.2006.07.001

67. Ji LL, Gomez-Cabrera MC, Vina J. Exercise and hormesis: activation of cellular antioxidant signaling pathway. Ann N Y Acad Sci. (2006) 1067:42535. doi: 10.1196/annals.1354.061
68. Halliwell B, Whiteman M. Measuring reactive species and oxidative damage in vivo and in cell culture: how should you do it and what do the results mean? Br J Pharmacol. (2004) 142:231-55. doi: 10.1038/sj.bjp.0705776

69. Jones RM, Mercante JW, Neish AS. Reactive oxygen production induced by the gut microbiota: pharmacotherapeutic implications. Curr Med Chem. (2012) 19:1519-29. doi: 10.2174/092986712799828283

70. Görlach A, Dimova EY, Petry A, Martínez-Ruiz A, HernansanzAgustín P, Rolo AP, et al. Reactive oxygen species, nutrition, hypoxia and diseases: problems solved? Redox Biol. (2015) 6:372-85. doi: 10.1016/j.redox.2015.08.016

71. Tornatore L, Thotakura AK, Bennett J, Moretti M, Franzoso G. The nuclear factor kappa B signaling pathway: integrating metabolism with inflammation. Trends Cell Biol. (2012) 22:557-66. doi: 10.1016/j.tcb.2012.08.001

72. Kamata H, Manabe T, Oka S, Kamata K, Hirata H. Hydrogen peroxide activates IkappaB kinases through phosphorylation of serine residues in the activation loops. FEBS Lett. (2002) 519:231-7. doi: 10.1016/s0014-5793(02)02712-6

73. Bokoch GM, Gilman AG. Inhibition of receptor-mediated release of arachidonic acid by pertussis toxin. Cell. (1984) 39:301-8. doi: 10.1016/0092-8674(84)90008-4

74. Kamada N, Nunez G. Regulation of the immune system by the resident intestinal bacteria. Gastroenterology. (2014) 146:1477-88. doi: 10.1053/j.gastro.2014.01.060

75. Vajro P, Paolella G, Fasano A. Microbiota and gut-liver axis: a mini-review on their influences on obesity and obesity related liver disease. J Pedeatr Gastroenterol Nutr. (2013) 56:461-8. doi: 10.1097/MPG.0b013e318284abb5

76. Musso G, Gambino R, Cassader M. Obesity, diabetes, and gut microbiota; the hygiene hypothesis expanded? Diabetes Care. (2010) 33:2277-84. doi: $10.2337 / \mathrm{dc} 10-0556$

77. Pierri L, Saggese P, Guercio Nuzio S, Troisi J, Di Stasi M, Poeta M, et al. Relations of gut liver axis components and gut microbiota in obese children with fatty liver: a pilot study. Clin Res Hepatol Gastroenterol. (2018) 42:38790. doi: 10.1016/j.clinre.2018.03.015

78. Valitutti F, Cucchiara S, Fasano A. Celiac disease and the microbiome. Nutrients. (2019) 11:2403. doi: 10.3390/nu11102403

79. Ni J, Wu GD, Albenberg L, Tomov VT. Gut microbiota and IBD: causation or correlation? Nat Rev Gastroenterol Hepatol. (2017) 14:573-84. doi: $10.1038 /$ nrgastro.2017.88

80. Prakash S, Rodes L, Coussa-Charley M, Tomaro-Duchesneau C. Gut microbiota: next frontier in understanding human health and development of biotherapeutics. Biologics. (2011) 5:71-86. doi: 10.2147/BTT.S19099

81. Poeta M, Pierri L, Vajro P. Gut-liver axis derangement in non-alcoholic fatty liver disease. Children. (2017) 4:66. doi: 10.3390/children4080066

82. Weissig V, Guzman-Villanueva D. Nanocarrier-based antioxidant therapy: promise or delusion? Expert Opin Drug Deliv. (2015) 12:1783-90. doi: 10.1517/17425247.2015.1063611

83. Migeotte I, Communi D, Parmentier M. Formyl peptide receptors: a promiscuous subfamily of $G$ protein-coupled receptors controlling immune responses. Cytokine Growth Factor Rev. (2006) 17:501-19. doi: 10.1016/j.cytogfr.2006.09.009

84. Zhang L, She ZG, Li H, Zhang XJ. Non -alcholic fatty liver disease: a metabolic burden promoting atherosclerosis. Clin Sci. (2020) 134:1775-99. doi: $10.1042 / C S 20200446$

85. Spadoni I, Zagato E, Bertocchi A, Paolinelli R, Hot E, Di Sabatino A, et al. A gut-vascular barrier controls the systemic dissemination of bacteria. Science. (2015) 350:830-4. doi: 10.1126/science.aad0135

86. De Goffau MC, Fuentes S, van den Bogert B, Honkanen H, de Vos WM, Welling GW, et al. Aberrant gut microbiota composition at the onset of type 1 diabetes in young children. Diabetologia. (2014) 57:1569-77. doi: 10.1007/s00125-014-3274-0

87. Banan A, Choudhary S, Zhang Y, Fields JZ, Keshavarzian A. Ethanolinduced barrier dysfunction and its prevention by growth factors in human intestinal monolayers: evidence for oxidative and cytoskeletal mechanisms. $J$ Pharmacol Exp Ther. (1999) 291:1075-85.

88. Varella Morandi Junqueira-Franco M, Ernesto Troncon L, Garcia Chiarello P, do Rosário Del Lama Unamuno M, Afonso Jordao A, Vannucchi 
H. Intestinal permeability and oxidative stress in patients with alcoholic pellagra. Clin Nutr. (2006) 25:977-83. doi: 10.1016/j.clnu.2006.03.010

89. Forsyth CB, Farhadi A, Jakate SM, Tang Y, Shaikh M, Keshavarzian A. Lactobacillus GG treatment ameliorates alcohol-induced intestinal oxidative stress, gut leakiness, and liver injury in a rat model of alcoholic steatohepatitis. Alcohol. (2009) 43:163-72. doi: 10.1016/j.alcohol.2008.12.009

90. Zhu L, Baker SS, Gill C, Liu W, Alkhouri R, Baker RD, et al. Characterization of gut microbiomes in nonalcoholic steatohepatitis (NASH) patients: a connection between endogenous alcohol and NASH. Hepatology. (2013) 57:601-9. doi: 10.1002/hep.26093

91. Guercio Nuzio S, Di Stasi M, Pierri L, Troisi J, Poeta M, Bisogno A, et al. Multiple gut-liver axis abnormalities in children with obesity with and without hepatic involvement. Pediatr Obes. (2017) 12:446-52. doi: $10.1111 /$ ijpo. 12164

92. Volynets V, Küper MA, Strahl S, Maier IB, Spruss A, Wagnerberger S, et al. Nutrition, intestinal permeability, and blood ethanol levels are altered in patients with nonalcoholic fatty liver disease (NAFLD). Dig Dis Sci. (2012) 57:1932-41. doi: 10.1007/s10620-012-2112-9

93. Clemente MG, Mandato C, Poeta M, Vajro P. Pediatric nonalcoholic fatty liver disease: recent solutions, unresolved issues, and future research directions. World J Gastroenterol. (2016) 22:8078-93. doi: 10.3748/wjg.v22.i36.8078

94. Jasirwan COM, Lesmana CRA, Hasan I, Sulaiman AS, Gani RA. The role of gut microbiota in non-alcoholic fatty liver disease: pathways of mechanisms. Biosci Microbiota Food Health. (2019) 38:81-8. doi: 10.12938/bmfh.18-032

95. Thakur V, Pritchard MT, McMullen MR, Wang Q, Nagy LE. Chronic ethanol feeding increases activation of NADPH oxidase by lipopolysaccharide in rat Kupffer cells: role of increased reactive oxygen in LPS-stimulated ERK1/ 2 activation and TNF-alpha production. J Leukoc Biol. (2006) 79:1348-56. doi: $10.1189 / \mathrm{jlb} .1005613$

96. Nobili V, Alisi A, Cutrera R, Carpino G, De Stefanis C, D’Oria V, et al. Altered gut-liver axis and hepatic adiponectin expression in OSAS: novel mediators of liver injury in paediatric non-alcoholic fatty liver. Thorax. (2015) 70:769-81. doi: 10.1136/thoraxjnl-2015-206782

97. Parola M, Vajro P. Nocturnal hypoxia in obese-related obstructive sleepapnea as a putative trigger of oxidative stress in pediatric NAFLD progression. J Hepatol. (2016) 65:470-2. doi: 10.1016/j.jhep.2016. 05.042

98. Sundaram SS, Halbower A, Pan Z, Robbins K, Capocelli KE, Klawitter J, et al. Nocturnal hypoxia-induced oxidative stress promotes progression of pediatric non-alcoholic fatty liver disease. J Hepatol. (2016) 65:560-9. doi: 10.1016/j.jhep.2016.04.010

99. Cakmak E, Duksal F, Altinkaya E, Acibucu F, Dogan O, Yonem O, et al. Association between the severity of nocturnal hypoxia in obstructive sleep apnea and non-alcoholic fatty liver damage. Hepat Mon. (2015) 15:e32655. doi: 10.5812/hepatmon.32655

100. Musso G, Olivetti C, Cassader M, Gambino R. Obstructive sleep apnea-hypopnea syndrome and nonalcoholic fatty liver disease: emerging evidence and mechanisms. Semin Liver Dis. (2012) 32:49-64. doi: 10.1055/s-0032-1306426

101. Mesarwi OA, Loomba R, Malhotra A. Obstructive sleep apnea, hypoxia, and nonalcoholic fatty liver disease. Am J Respir Crit Care Med. (2019) 199:830-41. doi: 10.1164/rccm.201806-1109TR

102. Young IS, Woodside JVJ. Antioxidants in health and disease. J Clin Pathol. (2001) 54:176-86. doi: 10.1136/jcp.54.3.176

103. Del Ben M, Polimeni L, Baratta F, Pastori D, Angelico F. The role of nutraceuticals for the treatment of non-alcoholic fatty liver disease. Br J Clin Pharmacol. (2017) 83:88-95. doi: 10.1111/bcp.12899

104. Trappoliere M, Caligiuri A, Schmid M, Bertolani C, Failli P, Vizzutti F, et al. Silybin, a component of silymarin, exerts anti-inflammatory and antifibrogenic effects on human hepatic stellate cells. J Hepatol. (2009) 50:110211. doi: $10.1016 /$ j.jhep.2009.02.023

105. Gillessen A, Schmidt HH. Silymarin as supportive treatment in liver diseases: a narrative review. Adv Ther. (2020) 37:1279-301. doi: 10.1007/s12325-020-01251-y

106. Gambini $J$, Inglés $M$, Olaso $G$, Lopez-Grueso $R$, Bonet-Costa $V$, Gimeno-Mallench L, et al. Properties of resveratrol: in vitro and in vivo studies about metabolism, bioavailability, and biological effects in animal models and humans. Oxid Med Cell Longev. (2015) 2015:837042. doi: $10.1155 / 2015 / 837042$

107. Tejada S, Capó X, Mascaró CM, Monserrat-Mesquida M, Quetglas-Llabrés $\mathrm{MM}$, Pons A, et al. Hepatoprotective effects of resveratrol in nonalcoholic fatty live disease. Current Pharmaceutical Design. (2020) 26:1. doi: 10.2174/1381612826666200417165801

108. Li S, Xu Y, Guo W, Chen F, Zhang C, Tan HY, et al. The impacts of herbal medicines and natural products on regulating the hepatic lipid metabolism. Front Pharmacol. (2020) 11:351. doi: 10.3389/fphar.2020.00351

109. Elvira-Torales LI, García-Alonso J, Periago-Castón MJ. Nutritional importance of carotenoids and their effect on liver health: a review. Antioxidants. (2019) 8:229. doi: 10.3390/antiox8070229

110. Lee Y, Hu S, Park YK, Lee JY. Health benefits of carotenoids: a role of carotenoids in the prevention of non-alcoholic fatty liver disease. Prev Nutr Food Sci. (2019) 24:103-13. doi: 10.3746/pnf.2019.24.2.103

111. de Freitas Carvalho MM, Lage NN, de Souza Paulino AH, Pereira RR, de Almeida LT, da Silva TF, et al. Effects of açai on oxidative stress, ER stress, and inflammation-related parameters in mice with high fat diet-fed induced NAFLD. Sci Rep. (2019) 9:8107. doi: 10.1038/s41598-019-44563-y

112. Zhu CG, Liu YX, Wang H, Wang BP, Qu HQ, Wang BL, et al. Active form of vitamin $\mathrm{D}$ ameliorates non-alcoholic fatty liver disease by alleviating oxidative stress in a high-fat diet rat model. Endocr J. (2017) 64:663-73. doi: 10.1507/endocri.EJ16-0542

113. Tagliaferri S, Porri D, De Giuseppe R, Manuelli M, Alessio F, Cena H. The controversial role of vitamin D as an antioxidant: results from randomised controlled trials. Nutr Res Rev. (2019) 32:99-105. doi: $10.1017 /$ S0954422418000197

114. Kitson MT, Roberts SK. D-livering the message: the importance of vitamin D status in chronic liver disease. J Hepatol. (2012) 57:897-909. doi: 10.1016/j.jhep.2012.04.033

115. Li Z, Zhang H, Li Y, Chen H, Wang C, Wong VKW, et al. Phytotherapy using blueberry leaf polyphenols to alleviate non-alcoholic fatty liver disease through improving mitochondrial function and oxidative defense. Phytomedicine. (2020) 69:153209. doi: 10.1016/j.phymed.2020.153209

116. Musolino V, Gliozzi M, Scarano F, Bosco F, Scicchitano M, Nucera S, et al. Bergamot polyphenols improve dyslipidemia and pathophysiological features in a mouse model of non-alcoholic fatty liver disease. Sci Rep. (2020) 10:2565. doi: 10.1038/s41598-020-594853

117. Vajro P, Mandato C, Franzese A, Ciccimarra E, Lucariello S, Savoia $\mathrm{M}$, et al. Vitamin $\mathrm{E}$ treatment in pediatric obesity-related liver disease: a randomized study. J Pediatr Gastroenterol Nutr. (2004) 38:48-55. doi: 10.1097/00005176-200401000-00012

118. Vajro P, Mandato C, Franzese A, Franzese A, Lucariello S. More on vitamin E therapy. Hepatology. (2004) 39:569-70. doi: 10.1002/hep.20036

119. Socha P, Horvath A, Vajro P, Dziechciarz P, Dhawan A, Szajewska H. Pharmacological interventions for nonalcoholic fatty liver disease in adults and in children: a systematic review. J Pediatr Gastroenterol Nutr. (2009) 48:587-96. doi: 10.1097/MPG.0b013e31818e04d1

120. Vajro P, Lenta S, Pignata C, Salerno M, D’Aniello R, De Micco I, et al. Therapeutic options in pediatric non alcoholic fatty liver disease: current status and future directions. Ital J Pediatr. (2012) 38:55. doi: 10.1186/1824-7288-38-55

121. Lavine JE, Schwimmer JB, Van Natta ML, Molleston JP, Murray KF, Rosenthal P, et al. Effect of vitamin E or metformin for treatment of nonalcoholic fatty liver disease in children and adolescents: the TONIC randomized controlled trial. JAMA. (2011) 305:1659-68. doi: 10.1001/jama.2011.520

122. Lomonaco R, Sunny NE, Bril F, Cusi K. Nonalcoholic fatty liver disease: current issues and novel treatment approaches. Drugs. (2013) 73:1-14. doi: 10.1007/s40265-012-0004-0

123. Harrison SA, Torgerson S, Hayashi P, Ward J, Schenker S. Vitamin $\mathrm{E}$ and vitamin $\mathrm{C}$ treatment improves fibrosis in patients with nonalcoholic steatohepatitis. Am J Gastroenterol. (2003) 98:2485-90. doi: 10.1111/j.1572-0241.2003.08699.x

124. Hoofnagle JH, Van Natta ML, Kleiner DE, Clark JM, Kowdley KV, Loomba $\mathrm{R}$, et al. Vitamin $\mathrm{E}$ and changes in serum alanine aminotransferase levels in patients with non-alcoholic steatohepatitis. Aliment Pharmacol Ther. (2013) 38:134-43. doi: 10.1111/apt.12352 
125. Chalasani N, Younossi Z, Lavine JE, Diehl AM, Brunt EM, Cusi K, et al. The diagnosis and management of non-alcoholic fatty liver disease: practice guideline by the American Association for the Study of Liver Diseases, American College of Gastroenterology, and the American Gastroenterological Association. Am J Gastroenterol. (2012) 107:811-26. doi: 10.1038/ajg.2012.128

126. Hashemian Z, Hashemi A, Fateminasab M. The Benefits of vitamin $\mathrm{E}$ on liver function and the hemopoietic system in thalassemia patients. Iran J Ped Hematol Oncol. (2012) 2:153-8.

127. Bell LN, Wang J, Muralidharan S, et al. Relationship between adipose tissue insulin resistance and liver histology in nonalcoholic steatohepatitis: a pioglitazone versus vitamin E versus placebo for the treatment of nondiabetic patients with nonalcoholic steatohepatitis trial follow-up study. Hepatology. (2012) 56:1311-8. doi: 10.1002/hep.25805

128. Abdel-Maboud M, Menshawy A, Menshawy E, Emara A, Alshandidy $M$, Eid $M$. The efficacy of vitamin $E$ in reducing non-alcoholic fatty liver disease: a systematic review, meta-analysis, and metaregression. Therap Adv Gastroenterol. (2020) 13:1756284820974917. doi: 10.1177/1756284820974917

129. Vivarelli F, Canistro D, Cirillo S, Papi A, Spisni E, Vornoli A, et al. Cocarcinogenic effects of vitamin E in prostate. Sci Rep. (2019) 9:11636. doi: 10.1038/s41598-019-48213-1

130. Hall KT, Buring JE, Mukamal KJ, Vinayaga Moorthy M, Wayne PM, Kaptchuk TJ, et al. COMT and alpha-tocopherol effects in cancer prevention: gene-supplement interactions in two randomized clinical trials. J Natl Cancer Inst. (2019) 111:684-94. doi: 10.1093/jnci/djy204

131. Ramirez-Tortosa MC, Ramirez-Tortosa CL, Mesa MD, Granados S, Gil A, Quiles JL. Curcumin ameliorates rabbit's steatohepatitis via respiratory chain, oxidative stress, and TNF-alpha. Free Radic Biol Med. (2009) 47:924-31. doi: 10.1016/j.freeradbiomed.2009.06.015

132. Chashmniam S, Mirhafez SR, Dehabeh M, Hariri M, Azimi Nezhad M, Nobakht M Gh BF. A pilot study of the effect of phospholipid curcumin on serum metabolomic profile in patients with non-alcoholic fatty liver disease: a randomized, double-blind, placebo-controlled trial. Eur J Clin Nutr. (2019) 73:1224-35. doi: 10.1038/s41430-018-0386-5

133. Mirhafez S, Farimani A, Gholami A, Hooshmand E, Tavallaie S, Nobakht $\mathrm{M}$ Gh BF. The effect of curcumin with piperine supplementation on prooxidant and antioxidant balance in patients with non-alcoholic fatty liver disease: a randomized, double-blind, placebo-controlled trial. Drug Metab Pers Ther. (2019) 34:20180040. doi: 10.1515/dmpt-2018-0040

134. Rahmani S, Asgary S, Askari G, Keshvari M, Hatamipour M, Feizi A, et al. Treatment of non-alcoholic fatty liver disease with curcumin: a randomized placebo-controlled trial. Phytother Res. (2016) 30:1540-8. doi: $10.1002 /$ ptr.5659

135. Rebiger L, Lenzen S, Mehmeti I. Susceptibility of brown adipocytes to pro-inflammatory cytokine toxicity and reactive oxygen species. Biosci Rep. (2016) 36:e00306. doi: 10.1042/BSR20150193

136. Di Minno MN, Russolillo A, Lupoli R, Ambrosino P, Di Minno A, Tarantino G. Omega-3 fatty acids for the treatment of non-alcoholic fatty liver disease. World J Gastroenterol. (2012) 18:5839-47. doi: 10.3748/wjg.v18.i41.5839

137. Yang J, Fernández-Galilea M, Martínez-Fernández L, González-Muniesa P, Pérez-Chávez A, Martínez JA, et al. Oxidative stress and non-alcoholic fatty liver disease: effects of omega-3 fatty acid supplementation. Nutrients. (2019) 11:872. doi: 10.3390/nu11040872

138. Erhardt A, Stahl W, Sies H, Lirussi F, Donner A, Häussinger D. Plasma levels of vitamin $\mathrm{E}$ and carotenoids are decreased in patients with Nonalcoholic Steatohepatitis (NASH). Eur J Med Res. (2011) 16:76-8. doi: 10.1186/2047-783x-16-2-76

139. Festi D, Schiumerini R, Eusebi LH, Marasco G, Taddia M, Colecchia A. Gut microbiota and metabolic syndrome. World J Gastroenterol. (2014) 20:16079-94. doi: 10.3748/wjg.v20.i43.16079

140. Hill C, Guarner F, Reid G, Gibson GR, Merenstein DJ, Pot B, et al. Expert consensus document. The International Scientific Association for Probiotics and Prebiotics consensus statement on the scope and appropriate use of the term probiotic. Nat Rev Gastroenterol Hepatol. (2014) 11:506-14. doi: 10.1038/nrgastro.2014.66
141. Ewaschuk JB, Dieleman LA. Probiotics and prebiotics in chronic inflammatory bowel diseases. World J Gastroenterol. (2006) 12:5941-50. doi: 10.3748/wjg.v12.i37.5941

142. Nanji AA, Khettry U, Sadrzadeh SM. Lactobacillus feeding reduces endotoxemia and severity of experimental alcoholic liver (disease). Proc Soc Exp Biol Med. (1994) 205:243-7. doi: 10.3181/00379727-205-43703

143. Di Caro S, Tao H, Grillo A, Elia C, Gasbarrini G, Sepulveda AR, et al. Effects of Lactobacillus GG on genes expression pattern in small bowel mucosa. Dig Liver Dis. (2005) 37:320-9. doi: 10.1016/j.dld.2004.12.008

144. Zhang L, Li N, des Robert C, Fang M, Liboni K, McMahon R, et al. Lactobacillus rhamnosus GG decreases lipopolysaccharide-induced systemic inflammation in a gastrostomy-fed infant rat model. J Pediatr Gastroenterol Nutr. (2006) 42:545-52. doi: 10.1097/01.mpg.0000221905.68781.4

145. Vajro P, Mandato C, Licenziati MR, Franzese A, Vitale DF, Lenta S, et al. Effects of Lactobacillus rhamnosus strain GG in pediatric obesityrelated liver disease. J Pediatr Gastroenterol Nutr. (2011) 52:740-3. doi: 10.1097/MPG.0b013e31821f9b85

146. Vajro P, Mandato C, Veropalumbo C, De Micco I. Probiotics: a possible role in treatment of adult and pediatric non alcoholic fatty liver disease. Ann Hepatol. (2013) 12:161-3. doi: 10.1016/S1665-2681(19)31401-2

147. Lei K, Li YL, Wang Y, Wen J, Wu HZ, Yu DY, et al. Effect of dietary supplementation of Bacillus subtilis B10 on biochemical and molecular parameters in the serum and liver of high-fat diet-induced obese mice. $J$ Zhejiang Univ Sci B. (2015) 16:487-95. doi: 10.1631/jzus.B1400342

148. Aviello G, Knaus UG. ROS in gastrointestinal inflammation: rescue or sabotage? Br J Pharmacol. (2017) 174:1704-18. doi: 10.1111/bph.13428

149. García-Lezana T, Raurell I, Bravo M, Torres-Arauz M, Salcedo MT, Santiago A, et al. Restoration of a healthy intestinal microbiota normalizes portal hypertension in a rat model of nonalcoholic steatohepatitis. Hepatology. (2018) 67:1485-98. doi: 10.1002/hep.29646

150. ClinicalTrials.gov. Bethesda, MD: National Library of Medicine (US). Identifier NCT02469272 Fecal Microbiota Transplantation (FMT) in Nonalcoholic Steatohepatitis (NASH). A Pilot Study (2017). Available online at: https://clinicaltrials.gov/ct2/show/NCT02469272 (assessed December 2020, 28).

151. Sangouni AA, Ghavamzadeh S. A review of synbiotic efficacy in nonalcoholic fatty liver disease as a therapeutic approach. Diabetes Metab Syndr. (2019) 13:2917-22. doi: 10.1016/j.dsx.2019.07.063

152. Saint-Georges-Chaumet Y, Edeas M. Microbiota-mitochondria inter-talk: consequence for microbiota-host interaction. Pathog Dis. (2016) 74:ftv096. doi: $10.1093 /$ femspd/ftv096

153. Lapenna D, Ciofani G, Festi D, et al. Antioxidant properties of ursodeoxycholic acid. Biochem Pharmacol. (2002) 64:1661-7. doi: 10.1016/s0006-2952(02)01391-6

154. Tang JT, Mao YM. Development of new drugs for the treatment of nonalcoholic steatohepatitis. J Dig Dis. (2020) 21:3-11. doi: 10.1111/1751-2980.12830

155. Zhu JB, Xu S, Li J, Song J, Luo B, Song YP, et al. Farnesoid X receptor agonist obeticholic acid inhibits renal inflammation and oxidative stress during lipopolysaccharide-induced acute kidney injury. Eur J Pharmacol. (2018) 838:60-8. doi: 10.1016/j.ejphar.2018.09.009

156. Navarro VJ, Belle SH, D’Amato M, Adfhal N, Brunt EM, Fried MW, et al. Silymarin in non-cirrhotics with non-alcoholic steatohepatitis: A randomized, double-blind, placebo controlled trial. PLoS ONE. (2019) 14:e0221683. doi: 10.1371/journal.pone.0221683

157. Jorgačević B, Vučević D, SamardŽić J, Mladenović D, Vesković M, Vukićević $\mathrm{D}$, et al. The effect of CB1 antagonism on hepatic oxidative/nitrosative stress and inflammation in nonalcoholic fatty liver disease. Curr Med Chem. (2020) 27:1. doi: 10.2174/0929867327666200303122734

158. Farzanegi P, Dana A, Ebrahimpoor Z, Asadi M, Azarbayjani MA. Mechanisms of beneficial effects of exercise training on non-alcoholic fatty liver disease (NAFLD): roles of oxidative stress and inflammation. Eur J Sport Sci. (2019) 19:994-1003. doi: 10.1080/17461391.2019.1571114

159. Chen Z, Tian R, She Z, Cai J, Li H. Role of oxidative stress in the pathogenesis of nonalcoholic fatty liver disease. Free Radic Biol Med. (2020) 152:116-41. doi: 10.1016/j.freeradbiomed.2020.02.025 
160. García-Ruiz C, Fernández-Checa JC. Mitochondrial oxidative stress and antioxidants balance in fatty liver disease. Hepatol Commun. (2018) 2:142539. doi: 10.1002/hep4.1271

161. Gottlieb A, Mosthael W, Sowa JP, Canbay A. Nonalcoholic-fatty-liver-disease and nonalcoholic steatohepatitis: successful development of pharmacological treatment will depend on translational research. Digestion. (2019) 100:79-85. doi: 10.1159/000493259

162. Ganguli S, DeLeeuw P, Satapathy SK. A review of current and upcoming treatment modalities in non-alcoholic fatty liver disease and non-alcoholic steatohepatitis. Hepat Med. (2019) 11:159-78. doi: 10.2147/HMER.S188991

163. Kim DY, Park JY. Genetic risk factors associated with NAFLD. Hepatoma Res. (2020) 6:85. doi: 10.20517/2394-5079.2020.96
Conflict of Interest: The authors declare that the research was conducted in the absence of any commercial or financial relationships that could be construed as a potential conflict of interest.

Copyright (C) 2021 Delli Bovi, Marciano, Mandato, Siano, Savoia and Vajro. This is an open-access article distributed under the terms of the Creative Commons Attribution License (CC BY). The use, distribution or reproduction in other forums is permitted, provided the original author(s) and the copyright owner(s) are credited and that the original publication in this journal is cited, in accordance with accepted academic practice. No use, distribution or reproduction is permitted which does not comply with these terms. 